\title{
Determination of Organic Acids in Wine and Spirit Drinks by Fourier Transform Infrared (FT-IR) Spectroscopy
}

\author{
UMESH REGMI ${ }^{1,2 *}$, KRISHNA PRASAD RAI ${ }^{2}$ and MIGUEL PALMA ${ }^{1}$ \\ ${ }^{1}$ University of Cadiz, Department of analytical chemistry, Puerto Real, Cadiz, Spain \\ ${ }^{2}$ Department of Food Technology and Quality Control, Kathmandu, Nepal
}

This study outlines the use of FTIR with partial least square (PLS) method and data obtained from the reference method is used to establish a full calibration model for tartaric acid, malic acid, lactic acid, succinic acid, citric acid and acetic acid using all matrix. It was not possible to obtain only one calibration for all analysed samples, but in some cases individual calibrations for specific samples were needed. It was due to the different matrixes in the studies samples: 12-15\% ethanol (wines), 30-40\% ethanol (spirits). Due to this reason, a calibration model was developed for each acid in red and white wine, and acetic acid in spirit drinks. During validation, strong correlation with the reference values and great accuracy were demonstrated for the higher concentration range $(>0.6 \mathrm{~g} / \mathrm{L})$ in all acids while inferior result was obtained in low range $(<0.6 \mathrm{~g} / \mathrm{L})$. But good result was obtained in lower concentration level both in wine and spirits in acetic acid, which explains that calibration and validation of the FTIR spectrometry depends very strongly on the composition of the sample set and on the quality of the reference analysis. The correlations for organic acids could further be improved with a more complete well distribution data base and optimizing wavelengths.

Keywords: FTIR Spectrometry, Organic acids, Wine, Spirit, Partial least square regression

\section{Introduction}

Low molecular weight organic acids are very important structural components in grape juice and wines and their balance has major implications both in sensory terms and for the stability. Wineries need to check the concentrations of organic acids during the winemaking process to ensure the quality of their wines. The $\mathrm{pH}$ is the main parameter to be controlled during winemaking to assure a microbiologically and chemically stable wine. The range between 3.1 and 3.4 $\mathrm{pH}$ value, which is suitable for most of the white wines and between 3.3 and 3.6 for most of the red wines.

In the case of wine, tartaric, malic and citric acids come directly from the grape and succinic, lactic and acetic acids are originated from the fermentation process (Ribéreau-Gayon et al., 2004). Tartaric acid, citric acid, malic acid may all be added legally to wine. The quantification of citric acid is important as wines destined for Europe must comply with regulations that specify that the citric acid level in wine must be below $1.0 \mathrm{~g} / \mathrm{L}$ (Tusseau and Benoit, 1987). Monitoring of Malic acid level is also important because many wines must undergo a process known as Malo-Lactic Fermentation (MLF), which "softens" the wine as malic acid is converted to lactic acid (Edwards and Bellman, 1989). Acetic acid is a by-product of the primary and secondary fermentation processes. A high concentration of acetic acid in wine is a strong indication that the grapes have been contaminated. These low molecular weight organic acids can affect the $\mathrm{pH}$ values dramatically and have implications on biological stability, sensory properties (Caccamo et al., 1986; Tusseau and Benoit, 1987) and colour of the wine (Garcia Romero et al., 1993). The profile of these polar compounds can be used for differentiation, classification,

\footnotetext{
*Corresponding author, E-mail: uregmi7@yahoo.com
}

origin identification or possible adulteration of beverages (Park et al., 1999).

Several methods (Spectrophotometric, enzymatic, nonenzymatic, chromatographic and electrophoretic methods) have been used for determination of level of organic acids for organic acids in grape juice, wines and spirits. But the winery need rapid, reliable, automatic, accurate and precise, cost effectiveness or no sample preparation analytical techniques allowing simultaneously measurement of a organic acids, providing immediate control over raw materials, over the characteristics of the finished product, thus ensuring that the wine and spirit drinks produced meets the expectations of increasingly demanding customers. The use of vibrational spectroscopy for routine analysis of wine began with Near Infrared Spectroscopy (NIR) being the preferred method in the early years. Recently, however, focus has moved towards FT-IR technology in the middle infrared region (Soriano et al., 2007) and has recently attracted attention to analyze wine and wineries products (Patz et al., 1999; Dubernet and Dubernet, 2000; Gishen and Holdstock, 2000; Kupina and Shrikhande, 2003). This technology is based on the measurement of the absorbance of radiation in the mid infrared region (4000-400/ $\mathrm{cm}$ ) by molecules that contain chemical bonds such as $\mathrm{C}=\mathrm{C}$, C-H, O-H, C=O and N-H (Smith, 1999).

The potential application of FT-IR spectroscopy in wine for the simultaneous determination of sugars, alcohols and organic acids based on multivariate evaluation of mid-IR transmission spectra has been reported by Schindler et al., 1998 and the first results comparing the FT-IR prediction with reference analysis was published by Patz et al.,1999 and evaluated FT-IR to analyse wine and must within 90s simultaneously on a significant number of important parameters along with tartaric acid, malic acid, lactic acid and citric acid (Patz et al., 
2004). While Spectroscopic interferences in Fourier transform infrared in wine analysis was studied by Moreira and Santos, (2004). Recently, FT-IR with PLS technique was applied for prediction of sugars and acids in Chinese rice wine (Shen et al., 2011). FT-IR was also used for the screening of the fermentation profiles of wine yeasts and also to detect early indications of wine fermentation problems (Nieuwoudt et al., 2006, Urtubia et al., 2008). In addition, FTIR spectroscopy has already been applied for characterisation and classification of wines, brandies or other distilled drinks according to origin, grape variety as well as manufacturing technique (Palma and Barroso, 2002; Cozzolino et al., 2009). The main objective of this work was to develop and validate a calibration model based on FT-IR for quantification of each organic acid using all matrixes. Otherwise, develop and validate individual calibration model for specific type of sample for accurate determination of organic acids (tartaric acid, malic acid, lactic acid, succinic acid, citric acid and acetic acid).

\section{Materials and Methods}

A total of 155 brandy samples, 138 white wines, 124 red wines, 17 sweet wines were analysed by using both reference method and FT-IR. The red wines consisted of wines from different origin and few Rosaline wines while white wines contained wines of different origin and some aged wines. The brandy samples covered the wide range of brandies including; Brandy de Jerez (Solera), Spanish Brandy, French brandy (Cognac) and South African Brandies. For each sample two duplicates were prepared for both reference and FT-IR method. In all cases, the samples were filtered through $0.45 \mu \mathrm{m}$ membranes before injection to HPLC system.

Reference method- The main organic acids (tartaric acid, malic acid, lactic acid, succinic acid, citric acid and acetic acid) were determined by reference method i.e. Ion Exclusion chromatography (IEC) with conductometric detection followed the method described by Guillén et al., (1998). The instrument arrangement comprised: two pumps Model 2150 and a Model 2155 oven for the columns, all from the LKB (Pharmacia, Sweden); a Model Conductomonitor III, conductivity detector from Milton Roy (LDC, Florida, USA); a Model 717 automatic injector and a Millenium data treatment system, both from Waters (Milford, MA, USA). Chromatographic separation was performed with a column model ROA-Organic Rezex Acidhead $+8 \%$, $300 \times 7.8 \mathrm{~mm}$, Phenomenex (Germany). The oven temperature was set at constant temp $60^{\circ} \mathrm{C}$. The flow rate used for both pump was
$0.40 \mathrm{ml} / \mathrm{min}$. The mobile phase used was a $2.5 \mathrm{mM}$ solution of trifluoroacetic acid (TFA) with a flow rate of $0.4 \mathrm{~mL} / \mathrm{min}$. A solution consisting of $2.5 \mathrm{mM}$ of TFA, $20 \mathrm{mM}$ of bis-tris buffer and $0.1 \mathrm{mM}$ of EDTA was added at the outlet of the column, by means of the second pump, at the flow rate of 0.4 $\mathrm{mL} / \mathrm{min}$. The software used for recording and processing was "Empower Pro 2002" (Waters).

Reference analysis- The standards of tartaric acid (99.5\%, Panreac), lactic acid $\quad(99.0 \%$, Fluka), citric acid $(99.0 \%$ Sigma- Aldrich) succinic acid (99.0\%, Fluka), malic acid (98-100\%, Sigma-Aldrich), acetic acid (Merck, Germany) were used to prepare calibration curve. $50 \mathrm{ml}$ of $50 \mathrm{~g} / \mathrm{L}$ standard stock solutions of tartaric acid, malic acid, lactic acid, succinic acid, citric acid and acetic acid were prepared in two different days. From the stock solution, $25 \mathrm{ml}$ of 10 working standard solutions starting from $0.1 \mathrm{~g} / \mathrm{L}$ to $10 \mathrm{~g} / \mathrm{L}$ of each acid were prepared by successive dilution with Milli-Q water. The calibration curve of each organic acid were prepared starting concentration $0.1 \mathrm{~g} / \mathrm{L}$ to $10 \mathrm{~g} / \mathrm{L}$ (full range) using peak area while Peak height was also used to prepare calibration curve of tartaric acid and citric acid to calculate concentration of these organic acids in real samples when partial overlapping peak occurs. In full range calibration curve of each acid, slope was changed into higher concentration. These curves were not suitable for calculation of concentration of acids present in real sample. The calibration curve of each acids were split in two part one was using lower concentration and next one is using higher concentration in order to adjust slope, linearity, determination of coefficient $\left(\mathrm{R}^{2}\right)$.

Similarly, Alamin computer programme (Canpana, 1997) was used to establish Limit of Detection (LOD), Limit of Quantification (LOQ) and linearity. The repeatability of the HPLC method was estimated as Relative Standard Deviation (RSD \%) of 6 replicates of the same sample analysed in the same day where as reproducibility of the HPLC method was calculated in terms of RSD (\%) of the 12 replicates of the same sample analysed in two consecutive days. Three different peaks, with different values and in three different parts of the chromatogram, were used for repeatability and reproducibility calculations Table 1 shows the linearity, LOD, LOQ, repeatability and reproducibility. The ranges for different samples studied were applied for calibration and validation of organic acid in this study is shown in Table 1.

Table 1. Final data of the HPLC method including LOD, LOQ, repeatability and reproducibility

\begin{tabular}{llllll}
\hline \multicolumn{1}{c}{ Organic acids } & $\begin{array}{c}\text { Linearity } \\
(\%)\end{array}$ & LOD $(\mathrm{g} / \mathrm{L})$ & LOQ $(\mathrm{g} / \mathrm{L})$ & $\begin{array}{c}\text { Reproducibility }(\mathrm{RSD} \%, \\
\mathrm{n}=6)\end{array}$ & $\begin{array}{c}\text { Repeatability } \\
(\mathrm{RSD} \%, \mathrm{n}=6)\end{array}$ \\
\hline Tartaric acid & 98.363 & 0.048 & 0.161 & 3.58 & \\
Citric acid & 98.763 & 0.048 & 0.162 & & \\
Malic acid & 98.029 & 0.059 & 0.198 & 5.24 & 6.65 \\
Succinic acid & 98.249 & 0.061 & 0.202 & & \\
Lactic acid & 97.476 & 0.072 & 0.240 & & \\
Acetic acid & 99.458 & 0.021 & 0.068 & 3.91 & 1.40 \\
Average & - & - & - & 4.24 & 3.52 \\
\hline
\end{tabular}


FTIR Spectroscopy- FT-IR equipment employed to obtain the spectra was a MultiSpec (TDI, Barcelona, Spain). The spectra were recorded between 0 and $7895 \mathrm{~cm}^{-1}$. The instrument was equipped with a model CETIM (TDI, Barcelona, Spain), Nicolet Avatar (Thermo) 370 source, detector, and beam splitter and auto sampler (40 trays). The Nicolet Avatar 370 had an Ever-Glow lamp as a source, a HP-DTGS-KBr detector and Potassium bromide (KBr) beam splitter. A sample volume of $7 \mathrm{ml}$ (standard setting) was pumped through the $10 \mathrm{ml}$ vial tube. The samples were filtered through filters of $0.45 \mu \mathrm{m}$ prior to their introduction in the unit. The working temperature was set at $25^{\circ} \mathrm{C}$. Analysis time took 60 s per sample. Cleaning was automatically programmed for every 5 vial tubes. Certain instrument settings cannot be changed by the user and these include the temperature at which samples are scanned $\left(25^{\circ} \mathrm{C}\right)$, the scanning interval $\left(0-7895 \mathrm{~cm}^{-1}\right.$ at $3.86 \mathrm{~cm}^{-1}$ intervals $)$, and conditions of spectral collection. The samples which were analyzed by the reference methods are also analyzed by FT-IR to obtain the infrared spectra. The duplicate of each samples were introduced into the FTIR system in the next day of the HPLC analysis of the same samples. A $10 \mathrm{ml}$ sample was required to run the sample into FT-IR system. No prior preparation of sample was required for brandy samples. In case of red and white wine samples, only those samples were filtered which had unclear and showed turbidity.

Multivariate data analysis- Wine must and brandy spectra are extremely multivariate and hence complex. It is necessary to use advanced mathematical techniques to generate the calibration equations for the individual acids. PLS regression as a multivariate calibration technique was used to perform quantitative measurements based on IR spectra. The spectra were exported to the Unscramble software (version 10.1, Camo ASA Norway) to do the calibration and validation. The selection of the wave number regions for calibration was performed taking into account both the chemical groups involved in each parameter and higher correlations between the instrumental response and the corresponding reference values for each parameter. Before the actual data analysis, the samples collective was checked for outliers to obtain robust models. Outlier detection is one of the most important tasks in practical multivariate calibration (Nieuwoudt et al., 2004). Outliers describe extreme deviating samples that show an abnormal pattern in variability when compared with other samples in a particular sample set (Esbensen, 2002).

For test set validation to verify and validate the results, 3 set of $25 \%$ of the samples was selected randomly from Microsoft Excel programme while three set of $75 \%$ samples were used for calibration of each acid. The three sets were then used independently for both calibration and validation and vice versa. This technique was adopted to display the stability of the calibration. In this case, the optimal number of PLS factors was selected based on the lowest Standard Error of Prediction (SEP). To test the predictive accuracy of the calibration models the validation of the methods was carried out using randomly selected validation set sample set.

Evaluation of the calibration and validation result- To evaluate the model a critical look on the statistical indicators for evaluating the accuracy of the predictive abilities of the new calibration models included bias, $\mathrm{R}^{2}$, and the prediction errors, Standard Error of Calibration (SEC) when based on the calibration sample sets, and SEP when based on independent validation sample sets was performed. But the validation result was evaluated based on the compare the prediction result to the reference value. A critical study on the IR relative error and HPLC relative error was performed. Average HPLC relative error was calculated for each acid using only those calibration curves which were used in this study. And a maximum error allowed for the FT-IR system was established by multiplying average relative error of HPLC by factor 3 shown in Table 2 . A criterion was established to distinguish between acceptable results and rejectable results. If the relative error of the predicted result was less than maximum error of each organic acid allowed for FT-IR system, those results were counted as acceptable results otherwise rejectable results.

Table 2. Criterion for evaluation of result using the FTIR method

\begin{tabular}{|c|c|c|c|}
\hline Organic acids & $\begin{array}{l}\text { Maximum error (relative } \\
\text { error) allowed for the } \\
\text { FTIR system }(\%)\end{array}$ & \multicolumn{2}{|c|}{$\begin{array}{l}\text { Samples showing relative errors below the maximum for each organic acid } \\
\text { (FTIR Relative error } \leq \text { Max. allowed error for FTIR system) }(\%)\end{array}$} \\
\hline Tartaric acid & 18.0 & $\geq 90$ & Excellent Quantification \\
\hline Malic acid & 26.7 & $\geq 70-89$ & Good Precision and Quantification \\
\hline Succinic acid & 19.5 & $\geq 50-69$ & $\begin{array}{l}\text { Good separation between low, medium and high values (good } \\
\text { screening) }\end{array}$ \\
\hline Lactic acid & 15.0 & \multirow{3}{*}{$\begin{array}{l}\geq 30-49 \\
\geq 5-29\end{array}$} & Correct separation between low and high values \\
\hline Citric acid & 15.0 & & Unsuitable for Quantification (It is better than no analysing \\
\hline Acetic acid & 15.0 & & \\
\hline
\end{tabular}




\section{Results and Discussion}

Reference analysis- The most abundant peak in the HPLC chromatogram in red and white wine samples was tartaric acid, succinic acid and acetic acid. The last peak was the peak of acetic acid which was free from other peaks and showing no overlapping with any other peak in all samples. In some brandy samples the most abundant peak was the peak of acetic acid but there were peak of tartaric acid, malic acid, lactic acid but their concentrations were very low $(<\mathrm{LOQ})$. In most of the red and white wine samples there was partial overlapping of peak with tartaric acid with citric acid.

Table 1, shows the limits of detection and quantification, repeatability and reproducibility of the organic acids by HPLC. The lowest detection $(0.021 \mathrm{~g} / \mathrm{L})$ and quantification $(0.068 \mathrm{~g} / \mathrm{L})$ limits were recorded for the acetic acid. RSD values for all organic acids were below $6.6 \%$ and $5.2 \%$. The range of concentration of each acid in real sample analysis is given in table 4. The value below the LOQ were not included in the table. Tartaric acid showed the good distribution of concentration range in wine samples ranging from 1 to $3.9 \mathrm{~g} / \mathrm{L}$ while malic, lactic and succinic acid had shown distribution of value in low and high level. The distribution of citric acid concentration level was between 0.2 to $0.6 \mathrm{gL}^{-1}$ and the level showed high in table 4 was sweet wine samples. The most of the acetic acid concentration level was in between 0.07-0.5 $\mathrm{g} / \mathrm{L}$. It was due to $80 \%$ brandy samples had low concentration level (0.07-0.2 g/L) and most of the red and white samples had range (0.1-0.7 g/L) except few samples had above this range. A normal distribution for all compounds was not found as different kind of samples was studied; however a full calibration was the first option during this work.

\section{FTIR analysis}

Spectral analysis- The main problems associated with organic acids determination in wine and wineries products by FT-IR spectroscopy and the associated multivariate data analysis are the acids under investigation are chemically very similar and therefore display similar IR absorption and dominating absorption of ethanol, water and in some cases, sugars strongly influences the determination of other components (Moreira and Santo, 2004; Patz et al., 2004). To solve these problems, it is necessary to select the relevant spectral wavelengths then to use PLS regression mathematics to optimise the calibration equations for each of the different parameters (Patz et al., 2004). To select the applicable wavelength, 12 replicates of the same sample, containing mixture of acid and ethanol, were prepared. These replicates were introduced into the FTIR system in the same day. The spectra obtained from the FTIR were exported in Microsoft Excel Programme and calculated the mean and standard deviation (SD) and RSD in each IR region. The regions, where the RSD was between 5 to $-5 \%$ were selected first in order to avoid the effect produce by the noise in calibration of the acids. The IR region $1543-1716$ $\mathrm{cm}^{-1}$ and $2970-3626 \mathrm{~cm}^{-1}$ is caused by water (Patz et al., 2004)and the region between $1050-1150 \mathrm{~cm}^{-1}$ is due to $\mathrm{C}-\mathrm{O}$ stretching of alcohol and contributes to substantial noise in the spectra. These regions were eliminated and not considered for calculation. But the peaks between $1700-1725 \mathrm{~cm}^{-1}$ are due to $\mathrm{C}=\mathrm{O}$ stretching of acid similarly peaks at $2500-3300 \mathrm{~cm}^{-1}$ are due to the $\mathrm{O}-\mathrm{H}$ stretching of the acid component and $1210-1321 \mathrm{~cm}^{-1}$ is due to $\mathrm{C}-\mathrm{O}$ stretching in acid . The peaks between $1157 \mathrm{~cm}^{-1}$ and $1504 \mathrm{~cm}^{-1}$ are due to $-\mathrm{CH}$ groups in the acid component, the absorption from 1200 to $1500 \mathrm{~cm}^{-1}$ also contains groups found in organic acid (Bevin et al., 2006). Considering these useful regions with eliminating the regions for not reproducible signal, the IR regions were selected for calibration and validation of organic acids is shown in Table 3.

Table 3: IR regions used for the calibration of the organic acids

IR selected region $\left(\mathrm{cm}^{-1}\right)$

$933.42-1010.57$
$1153.28-1211.14$
$1226.57-1465.71$
$1477.28-1550.56$
$1716.42-1739.56$
$1758.85-2318.13$
$2410.7-2969.77$

Calibration and validation results- With the purpose of to achieve with its objective, red wine, white wine, sweet wine and brandy samples were selected to make representative sample set. The selection of samples were important, in order to make robust calibration models. FT-IR is a vanguard method. So, it was first necessary to calibrate the instrument against the reference method. All samples analyzed with the reference methods were also tested by FTIR to obtain the infrared spectra. These Spectra were exported to Unscramble software (version 10.1, Camo ASA, Norway) and PLS was chosen for calibration. At this step, it is important to get maximum explained variance with lower number of variables and the minimum SEC. Usually, this value decreases as the number of principle factor increases. In order to check the model is fit for quantification for organic acids using all matrixes, firstly, calibration was performed for all organic acids including all samples. Table 4, shows the initial calibration result without removing outliers including red, white and sweet wine in tartaric, malic, lactic, and red, white sweet wine and brandy samples in acetic acid. 
Table 4. Calibration results including all samples

\begin{tabular}{llll}
\hline Organic acids & PLS Factors & $\mathbf{R}^{\mathbf{2}}$ & SEC(g/L) \\
\hline Tartaric acid $^{\mathrm{a}}$ & 14 & 0.86 & 0.19 \\
Malic acid $^{\mathrm{a}}$ & 8 & 0.89 & 0.29 \\
Lactic acid $^{\mathrm{a}}$ & 12 & 0.93 & 0.22 \\
Succinic acid $^{\mathrm{a}}$ & 8 & 0.93 & 0.15 \\
Citric acida & 9 & 0.89 & 0.10 \\
Acetic acid & 11 & 0.94 & 0.064 \\
\hline
\end{tabular}

${ }^{\mathrm{a}}$ Samples including red, white and sweet wine $^{\mathrm{b}}=$ samples including red, white, sweet and brandy samples

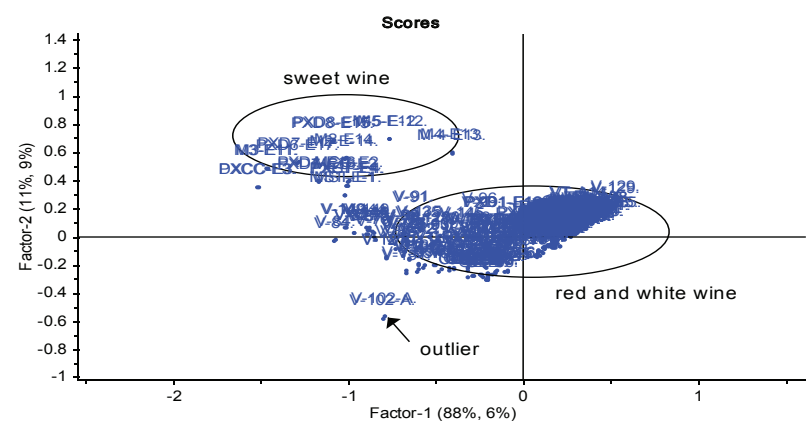

(A)

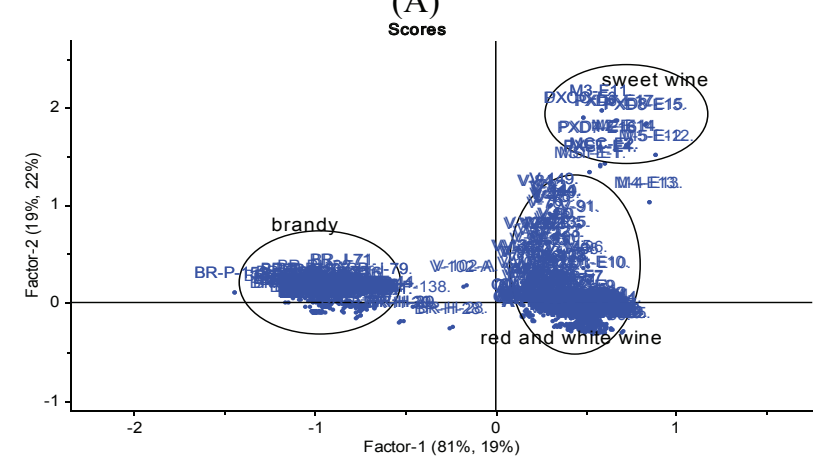

(B)

Figure 1. Score plot of (A) tartaric acid (B) acetic acid, showing samples in group

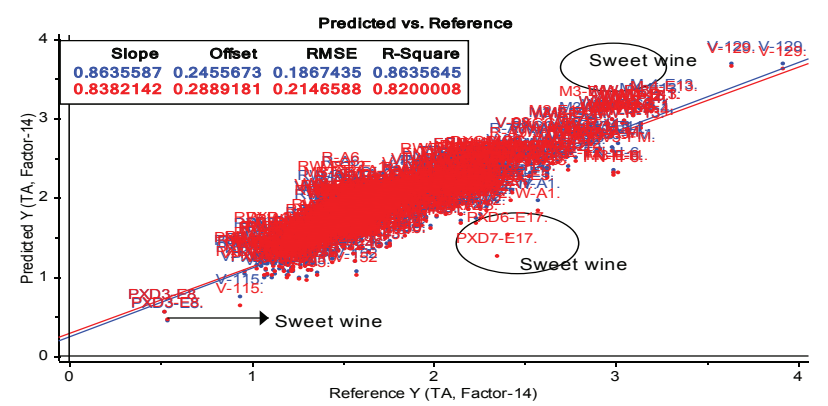

Figure 2. Calibration result of tartaric acid with red, white and sweet wine samples

The calibration model (Table 4) was good enough for winemakers to check evolution of organic acids in wine, brandy and vinegar samples but a robust model was very important in this study. For this score plot of each acid, $x-y$ relation outliers plot and calibration curve were studied. Figure 1 score plot depicts the nature of the samples. Samples were grouped according to the similar constituents present. The calibration model was badly described by sweet wine samples in all acids as shown in Figure 2 in tartaric acid where sweet wine samples were markedly deviated from the calibration line. It could be due to presence of sugar in sweet wine sample making noise in the calibration. Having only few samples, sweet wines were removed from the calibration set. Again the score plot and X-Y relation outliers used to identify outliers a calibration model of each acid was build after removing outliers while brandy samples were included along with red and white wine samples in acetic acid. Table 5 shows the calibration and validation summary in full range.

The total samples shown in Table 5 were the no. of samples after removing outliers and these samples were used for calibration. To check the ruggedness of that calibration model, the sample set was divided into three independent calibration set and validation set and used independently for calibration and validation. Using three calibration and validation set the values were calculated taking average from there independent calibration and validation sets shown in Table 5. In full range calibration set, there was excellent result in tartaric acid $\left(\mathrm{R}^{2}=0.90\right)$, malic acid $\left(\mathrm{R}^{2}=0.96\right)$, lactic acid $\left(\mathrm{R}^{2}=0.95\right)$, succinic acid $\left(\mathrm{R}^{2}=0.95\right)$ and excellent prediction result in tartaric acid $\left(\mathrm{R}^{2}=0.90\right)$, malic acid $\left(\mathrm{R}^{2}=0.95\right)$, lactic acid $\left(R^{2}=0.94\right)$, succinic acid $\left(R^{2}=0.94\right)$, with low SEP value. But the validation result was again evaluated as explained above (samples in three validation set showing less error than maximum allowed for FTIR system), where as $97 \%$ samples were in acceptable range in tartaric acid, which explained that this model is excellent for quantification of tartaric acid but for malic, and succinic acid it was $80 \%$ and $75 \%$ where as lactic acid validation set had shown low performance (only $60 \%$ lactic acid sample was in acceptable criterion). However, the full range calibration model of malic and lactic acid will be supportive for winemakers to check MLF. When malic acid goes below $0.6 \mathrm{~g} / \mathrm{L}$, it indicates MLF is running, so the interest on its determination decreases below $0.6 \mathrm{~g} / \mathrm{L}$ and lactic acid starts to be determined.

From above malic, lactic and succinic acid full range calibration and validation results, it explained that judging the quality of a calibration model based solely on the $\mathrm{R}^{2}$ statistics can sometimes lead to misinterpretation in the case of a non- normally distributed sample set where concentrations are grouped in two distinct ranges, the $\mathrm{R}^{2}$ value can suggest that the correlation is better but prediction results are poor. Due to this, a critical look to the data distribution, and also to SEP and SEC is also essential. To check the influences of the concentration level on the calibration model a plot was drawn between FTIR relative error $v s$. Reference value for malic, lactic, and succinic acid is shown in Figure 3. 
Table 5. Calibration and validation summary in full, low and high range

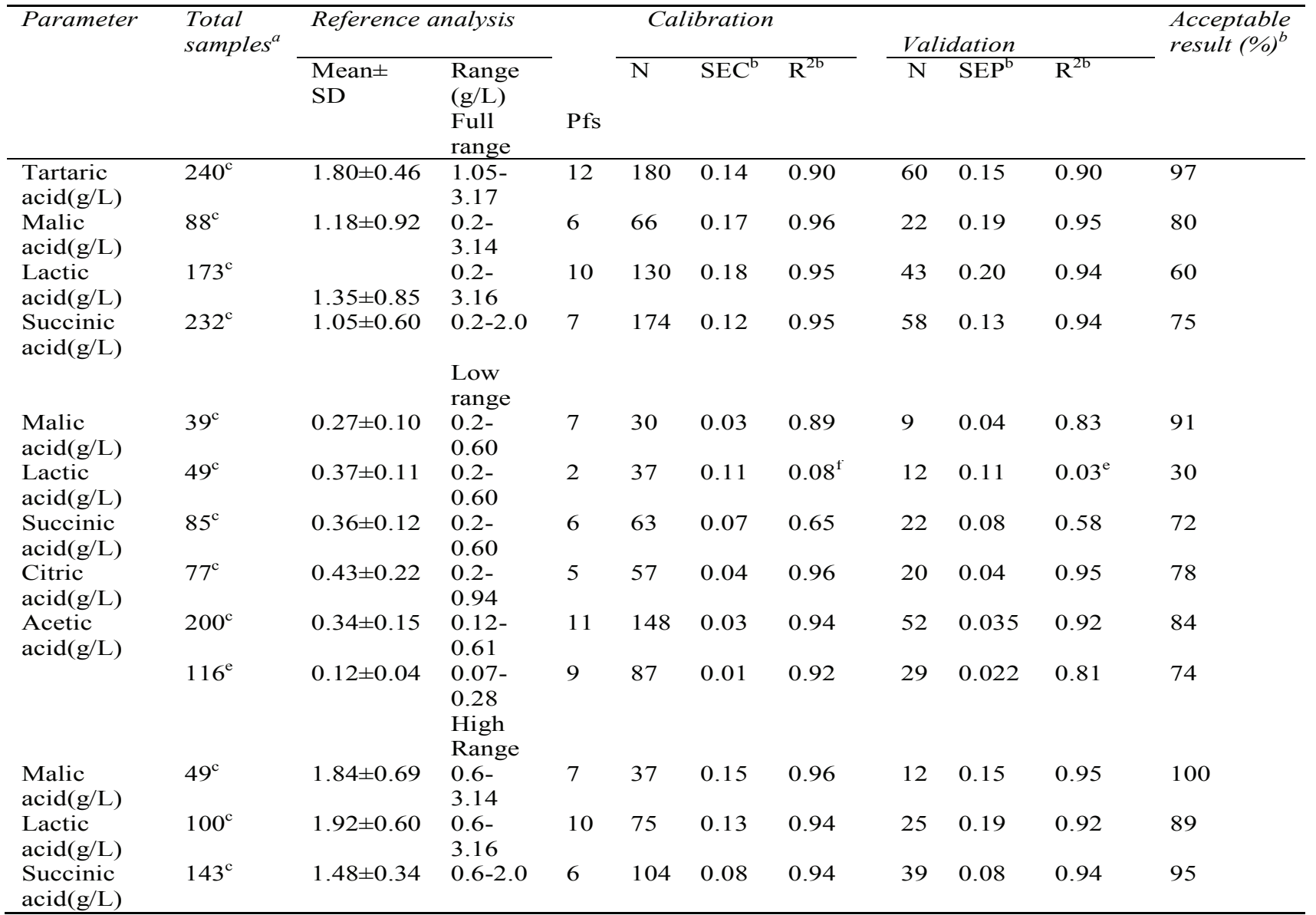

${ }^{a}=$ Total samples after removing outliers, ${ }^{b}=$ Average value from three independent calibration and validation set, $^{c}=$ samples set containing only red and white wines, ${ }^{d}=$ samples set containing red, white wines, spirit drinks and vinegar samples, $\stackrel{e}{=}$ Samples only spirit drinks, $f=$ Value inside the range of non-significance, pfs $=$ Principal factors, Acceptable result $=$ Samples in validation set showing less error than maximum allowed error for FTIR system
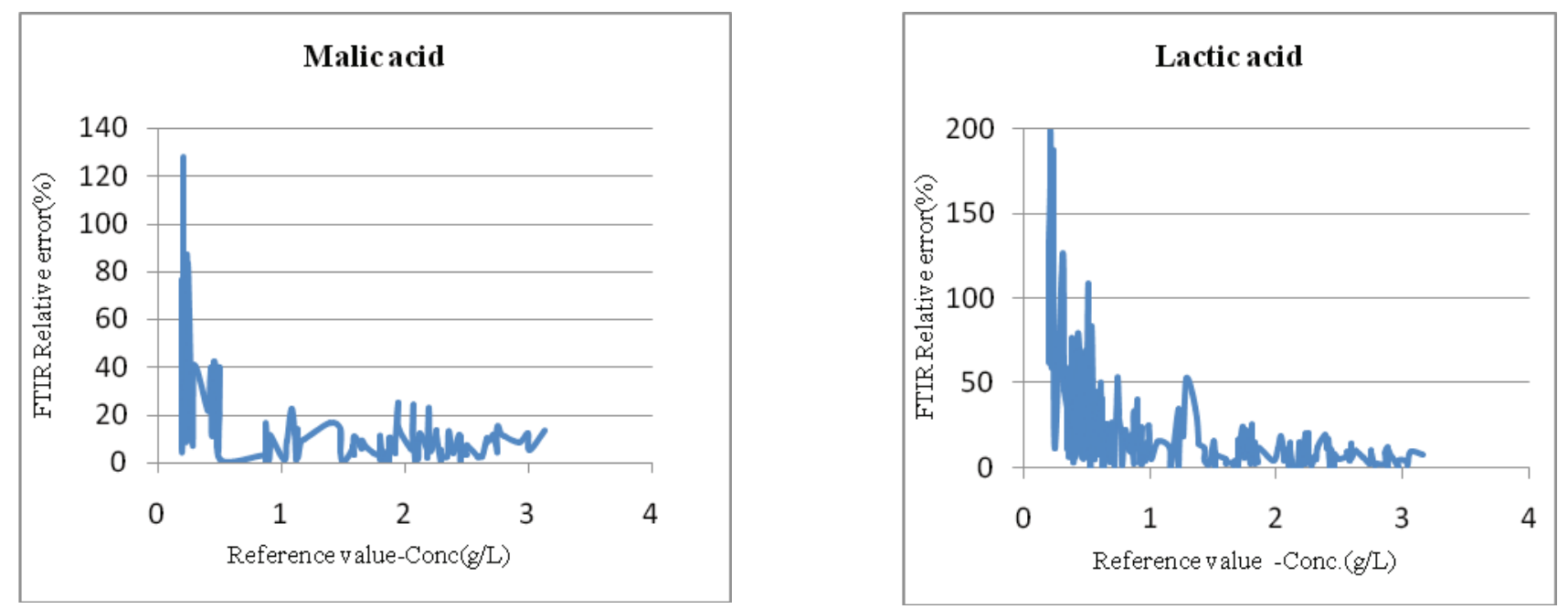


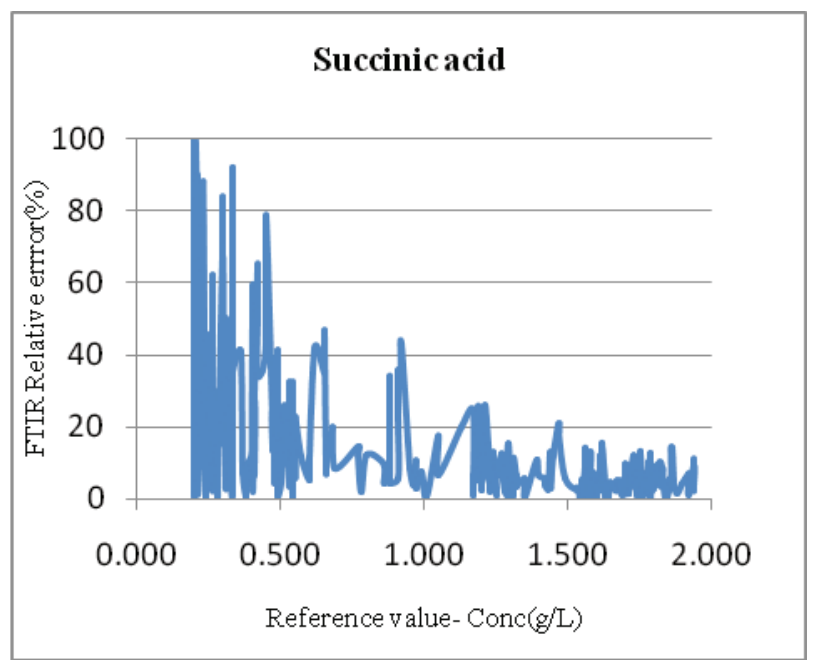

Figure 3. Validation result of organic acids in three validations set

Figure 3, clearly depicts that main errors are found mainly in low levels, as it has happened for the reference method and a non linear regression in the full range was supposed for FTIR regression where as origin of the samples didn't play for high error. Due to this reason, the sample set was divided into the low concentration and high concentration range for malic, lactic and succinic acid. In case of acetic acid, the sample set was divided according to the matrix which was almost related to concentration range. A red and white wine sample set was $0.1-0.8 \mathrm{~g} / \mathrm{L}$ and brandy sample set was 0.07 to $0.28 \mathrm{~g} / 1$.

Table 5 shows the average result of three calibration and prediction set of the low and high concentration range. It is expected that compounds with identical or very close absorption bands should be affected by those of others present in higher concentrations. It is expected that the analytical calibration of compounds present in low concentration should be affected by other compounds with identical or very close IR absorption bands, present in higher concentration. In case of malic and lactic acid, samples which contained low concentration of lactic acid had high concentration of malic acid and vice versa. The good validation result of malic acid could be structural configuration (two carboxy group and $\mathrm{O}-\mathrm{H}$ bond of secondary alcohol); however, large data set is necessary to perform the calibration model. Due to high concentration of tartaric acid, the performance of succinic acid in lower concentration could be affected due to similar absorption band of tartaric and succinic acid and also the concentration level were below $0.6 \mathrm{~g} / \mathrm{L}$, some being close to LOQ. The one more reason for the poor performance could be attributed to the accuracy of the reference method; high relative error was shown by reference method in low range. It is also known that succinic and acetic acid do not have the alcohol functional group, and therefore lacking the $\mathrm{C}-\mathrm{O}$ and $\mathrm{O}-\mathrm{H}$ bond from the secondary alcohol that the other organic acids have. Good performance calibration model compare to other acids in low range was obtained for citric acid. It could be the molecular configuration of citric acid ( 3 carboxy group, two $\mathrm{O}-\mathrm{H}$ bond of secondary alcohol). But acetic acid had shown good result in lower range in wine and spirit drinks however the concentration range of acetic acid in spirit drink was very low. In any mode, the FT-IR measurement is based upon the predictive ability of the reference method. In acetic acid measurement, in reference analysis, there were no interferences while measuring acetic acid and was low relative error in low concentration level which explains the excellent predictive ability of acetic acid in reference method. In addition, reference calibration curve was split low level as explained above 0.1 to $1.5 \mathrm{~g} / \mathrm{L}$ in both citric and acetic acid in order to do standard analysis because of the low concentration level in real samples. This was contrary in case of malic, lactic and succinic acid. In those acids the reference calibration curve was divided in high level $(0.2-4.0 \mathrm{~g} / \mathrm{L}$ for malic and lactic acid, $0.2-2.0 \mathrm{~g} / \mathrm{L}$ for succinic acid). Those samples which showed high error in malic, lactic and succinic acid had concentration value near above LOQ, it was almost similar when compare to reference method. According to $\mathrm{R}^{2}$ and validation result, the calibration model of acetic can be used for quantification purposes in red and white wine and in spirit drinks.

In high range calibration and validation table 6 shows lowest SEC was obtained using less number of PLS factors when compare the full range prediction. Based on the prediction result (100\% sample of malic acid, $95 \%$ sample of succinic acid and $89 \%$ of lactic acid sample were in acceptable range) and excellent $\mathrm{R}^{2}$ value for malic acid (0.96), lactic acid (0.94) and succinic acid (0.94) was obtained, these calibration curves are excellent for quantification of malic, succinic and lactic acid in red and white wine samples above concentration range $0.6 \mathrm{~g} / \mathrm{L}$ which explained that during performing calibration, data distribution is critical to obtain a robust calibration.

\section{Conclusion}

In this study, FTIR was used in combination with multivariate techniques to accomplish the rapid, reliable and affordable determination of organic acids in wine and spirit drinks. A calibration model was developed for each organic acid in low range $(>0.6 \mathrm{~g} / \mathrm{L})$ and high range $(<0.6 \mathrm{~g} / \mathrm{L})$ concentration level in red and white wine samples and acetic acid in brandy samples. The calibration and validation process of tartaric acid, malic acid, succinic acid, and lactic acid in high concentration level showed excellent result, while poor result obtained in low concentration level. But FTIR performance was satisfactory in malic acid and citric acid in low level and good result in acetic acid in red and white wine and brandies samples, however the concentration of acetic acid was very low in brandy samples, which proved that FT-IR is highly dependent upon the predicting ability of the reference method, composition of the sample set with concentration range covered by the samples and molecular configuration of the analyte. 


\section{Acknowledgments}

The first author thanks Professor Miguel Palma to act as supervisor to run this thesis and the Education, Audiovisual and Culture Executive Agency (EACEA) for a fellowship to run the master thesis.

\section{References}

Caccamo F., Carfagnini G., Corcia Di A. and Samperi R. (1986). Improved High Performance Liquid Chromatographic assay for determining Organic acids in wines. J. Chrom., 362:47-53.

Cozzolino D., Holdstock M., Dambergs Robert G., Cynkar Wies U., Smith Paul A. (2009). Mid infrared spectroscopy and multivariate analysis: A tool to discriminate between organic and non-organic wines grown in Australia. Food Chem., 116: 761-765.

Dubernet M. and Dubernet M. (2000). Utilisation de l'analyse infrarouge à transformée de Fourier pour l'analyse oenologique de routine. Rev. Fr. OEnol. 181, 10-13

Edwards C. G. and Beelman R. B. (1989). Inducing Malolactic fermentation in wines. Biotech. Adv. Vol. 7, pp 333-360.

Esbensen K. H. (2002). Multivariate data analysis - In practise, 5th ed., Camo ASA, Oslo Martens H. and Naes T. (1989). Multivariate calibration. Wiley, New York.

García-Romero E., Snchez-Mucoz G., Martvn-Гlvarez P. J. and Cabezudo-Ibnez M. D. (1993). Determination of organic acids in grape musts, wines and vinegars by high-performance liquid chromatography. J. of Chr. 655: 111-117.

Gishen M. and Holdstock M. (2000). Preliminary evaluation of the performance of the Foss WineScan FT 120 instrument for the simultaneous determination of several wine analyses. Australian Grapegrower Winemaker, Annual Technical Issue, 75-81.

Guillén D. A., Barroso C. G., Zorro L., Carrascal V., PérezBustamante J. A. (1998). Organic acids analysis in "Brandy de Jerez" by ion-exclusion chromatography, Post-column buffering and conductimetric detection. Analysis, 26, 186-189.

Kupina S. A. and Shrikhande A. J. (2003). Evaluation of a Fourier Transform Infrared Instrument for Rapid Quality-Control Wine Analyses. Am. J. Enol. Vitic. 54 (2):131-134.

Moreira J. L., Santos L. (2004). Spectroscopic interferences in Fourier transform infrared wine analysis. Anal. Chimica Acta, 513: 263-268.

Moreira J. L., Santos L. (2005). Analysis of organic acids in wines by Fourier-transform infrared spectrocopy. Anal. Bioanal. Chem, 382: 421-425.
Nieuwoudt H. H., Prior B. A., Pretorius I. S., Manley M. and Bauer F. F. (2004). Principal component analysis applied to Fourier Transform Infrared spectroscopy for the design of calibration sets for glycerol prediction models in wine and for the detection and classification of outlier samples. J. Agric. Food. Chem. 52: 3726-3735.

Palma M. and Barroso C. G. (2002). Application of FT-IR spectroscopy to the characterisation and classification of wines, brandies and other distilled drinks. Talanta, $58,265-271$.

Park Y. J., Kim K. R. and Kim J. H. (1999) Gas Chromatographic Organic Acid Profiling Analysis of Brandies and Whiskeys for Pattern Recognition Analysis, J. Agric. Food Chem. 47,2322-2326.

Patz C. D., David A., Thente K., Kürbel P. and Dietrich H. (1999). Wine analysis with FTIR spectrometry. Viticultural and Enological Sci. 54: 80-87.

Patz C. D., Blieke, A., Ristow, R. and Dietrich H. (2004). Application of FT-MIR spectrometry in wine analysis. Anal. Chim. Acta, 513: 81-89.

Ribéreau-Gayon P., Glories Y., Maujean A., Dubourdieu D. (2004). Handbook of Enology. Volume 2. The chemistry of Wine Stabilization and Treatments. John Wiley \& Sons, Ltd., West Sussex, PO19 8SQ, England.

Schindler R., Vonach R., Lendl B., Kellner R. (1998). A rapid automated method for wine analysis based upon sequential injection (SI)-FTIR spectrometry. Fresenius J. Anal. Chem. 362: 130-136.

Shen F., Ying Y., Li B., Zheng Y., Hu J. (2011). Prediction of sugars and acids in Chinese rice wine by mid-infrared spectroscopy. Food Res. Int., 44: 1521-1527.

Smith B. (1999). Infrared spectral interpretation: A systematic approach (1st Ed.). Boca Raton: CRC Press LLC.

Soriano A., Pérez-Juan P. M., Vicario A., González J. M. and Pérez-Coello M. S. (2007). Determination of anthocyanins in red wine using a newly developed method based on Fourier transform infrared spectroscopy. Food Chem. 104 (3): 1295-1303.

Tusseau D. and Benoit C. (1987). Routine high-performance liquid chromatographic determination of carboxylic acids in wines and champagne. J. of Chr., 395: 323-333.

Urtubia A., Pérez-correa J. R., Pizarro F. and Agosin E. (2008). Exploring the applicability of MIR spectroscopy to detect early indications of wine fermentation problems. Food Cont., 19: 382-388. 